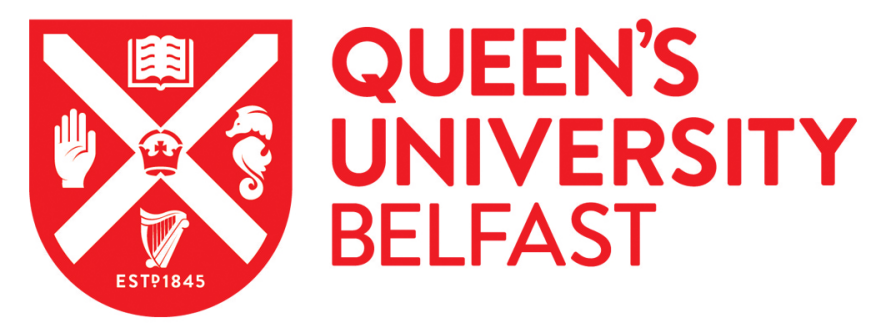

\title{
ABCB1 gene polymorphisms and response to chemotherapy in breast cancer patients: a meta-analysis
}

Madrid-Paredes, A., Canadas Garre, M. L., Sanchez-Pozo, A., Exposito Ruiz, M., \& Calleja Hernandez, M. A. (2017). ABCB1 gene polymorphisms and response to chemotherapy in breast cancer patients: a meta-analysis. Surgical Oncology. https://doi.org/10.1016/j.suronc.2017.09.004

Published in:

Surgical Oncology

Document Version:

Peer reviewed version

Queen's University Belfast - Research Portal:

Link to publication record in Queen's University Belfast Research Portal

\section{Publisher rights}

Copyright 2017 Elsevier.

This manuscript is distributed under a Creative Commons Attribution-NonCommercial-NoDerivs License

(https://creativecommons.org/licenses/by-nc-nd/4.0/), which permits distribution and reproduction for non-commercial purposes, provided the author and source are cited.

\section{General rights}

Copyright for the publications made accessible via the Queen's University Belfast Research Portal is retained by the author(s) and / or other copyright owners and it is a condition of accessing these publications that users recognise and abide by the legal requirements associated with these rights.

Take down policy

The Research Portal is Queen's institutional repository that provides access to Queen's research output. Every effort has been made to ensure that content in the Research Portal does not infringe any person's rights, or applicable UK laws. If you discover content in the Research Portal that you believe breaches copyright or violates any law, please contact openaccess@qub.ac.uk. 


\section{ABSTRACT}

The ABCB1 gene encodes the P-glycoprotein, an efflux pump for some antineoplastic agents which acts as a resistance mechanism to chemotherapy. Three SNPs (C3435T, C1236T and G2677T/A), are the most widely studied in ABCB1. The inconsistent conclusions about the association of these polymorphisms and the response to chemotherapy in breast cancer (BC) patients prompted us to conduct a meta-analysis.

A total of nine (770 patients), five (566 patients) and three studies (367 patients) relating the $\mathrm{ABCB} 1 \mathrm{C} 3435 \mathrm{~T}, \mathrm{C} 1236 \mathrm{~T}$ and $\mathrm{G} 2677 \mathrm{~T} / \mathrm{A}$ polymorphisms respectively, were included.

The main analysis revealed a lack of association between $A B C B 1$ polymorphisms and response to chemotherapy in every genetic model: C3435T (dominant OR: 0.888 ; 95\% $\mathrm{Cl}:$ 0.558-1.413), C1236T (dominant OR: 1.968; 95\% Cl: $0.609-6.362$ ) and G2677T/A (GG vs GT+GA+TT+TA+AA OR: 0.854; 95\%Cl: 0.418-1.744). Stratification by ethnicity, cancer type and response criteria did not change the pattern of results.

The available evidence indicates that three polymorphisms within ABCB1; C3435T, C1236T and G2677T/A, cannot be considered a reliable predictor of response to chemotherapy in BC patients. ${ }^{1}$

\section{KEYWORDS}

META-ANALYSIS

\section{$\mathrm{ABCB} 1$}

\footnotetext{
${ }^{1}$ ABCB1 (ATP-binding cassette, B1), ACT (Adjuvant Chemotherapy), BC (Breast Cancer), FAC (Fluouracil-Adryamicin-Cyclophosphamide), FEC (Fluouracil-Epirubicin-Cyclophosphamide), LABC (Locally Advance Breast Cancer), MBC (Metastatic Breast Cancer), NACT (Neoadjuvant Chemotherapy), SNP (Single Nucleotide Polymorphism)
} 
C3435T

C1236T

BREAST

CANCER

\section{INTRODUCTION}

Breast cancer $(\mathrm{BC})$ is the most common cause of cancer-related death in women in the world [1]. In the recent decades, substantial progress has been made in the treatment of BC. BC patients are treated neoadjuvantly (prior surgery) or adjuvantly with chemotherapy, HER2-targeted drugs (if HER2-positive), hormonal therapy, or a combination of these. The chemotherapeutic drugs which are most commonly used against BC include anthracyclines (doxorubicin and epirubicin) and taxanes (paclitaxel and docetaxel). These can be used in combination with fluorouracil (5-FU), cyclophosphamide and/or carboplatin [2]. Chemotherapy with anthracyclines or taxanes has shown impressive response rates. Polychemotherapy with anthracycline and cyclophosphamide showed better results compared to the cyclophosphamidemethotrexate-fluorouracil scheme [3]. Patients treated with taxane-based schemes at first or second-line have shown high response rates [2]. However, there is a low to moderate risk of recurrence [4].

Clinical factors including stage, size of the tumour, number of lymph nodes involved, hormonal receptors or HER2 status, alter the response to chemotherapy [5]. Other mechanisms, such as genetic differences in drug transporters, may contribute to the inter-individual variations in treatment outcomes [6]. The ATP-binding cassette, B1 (ABCB1) gene encodes the P-glycoprotein, an efflux pump for some antineoplastic agents (anthracyclines, taxanes or tamoxifen) which acts as a resistance mechanism to chemotherapy $[7,8]$. Three single nucleotide polymorphisms (SNPs); C1236T (rs1128503), C3435T (rs1045642) and G2677T/A (rs2032582), are the most widely 
studied SNPs in ABCB1 [9]. While the ABCB1-2677G>T/A gene polymorphism results in an amino-acid change from Ala to Ser/Thr at codon 893, the 1236C>T (Gly412Gly) and 3435C>T (lle1144lle) SNPs are synonymous [10].

\subsection{ABCB1- C3435T}

The association between the ABCB1-C3435T gene polymorphism and treatment outcomes response in BC patients treated with neoadjuvant chemotherapy remains controversial. A meta-analysis published in 2012, including 7 studies (464 patients), found no influence between the ABCB1-C3435T gene polymorphism and treatment response in $B C$ patients [11]. Recent studies have shown an association of the ABCB1-C3435T gene polymorphism with treatment response, although they differ in the positive effect of the T-allele on the response [12,13]. In $148 \mathrm{BC}$ patients treated with neoadjuvant chemotherapy, the ABCB1-C3435T T-allele carriers had a higher response (T-allele vs CC: $43.4 \%$ vs $23.8 \%$, OR: $2.695 ; p=0.02$ ) [12], whereas in 153 $\mathrm{BC}$ patients also treated with neoadjuvant chemotherapy, the $\mathrm{C}$-allele was associated with higher response (C-allele vs TT: 71.2 vs 33.3\%, $p=0.001)$ [13].

A more recent meta-analysis including 8 studies (608 cases) found no association between the treatment response and the dominant model (CT + TT vs CC) of the ABCB1-C3435T gene polymorphism (OR: 1.13; 95\% Cl: 0.58-0.37; $p=0.71$ ) [14]. More recently, no association has been found either in a study of Kurdish BC patients (100 cases/200 controls) [15] or in 83 BC patients treated with chemotherapy plus trastuzumab [16].

\subsection{ABCB1- C1236T}

T-allele carriers of the ABCB1-C1236T gene polymorphism showed worse response (T-allele vs CC: $58.3 \%$ vs $85 \%$; OR non-responders/responders: $4.63 ; p=0.021$ ) in 100 BC patients treated with neoadjuvant chemotherapy [14]. These results were further confirmed in other studies (Agarwal: 2015fk, Tulsyan: 2014cy\}. However, a meta- 
analysis conducted in 2013 by these authors, which included 3 studies (373 patients), found no association between the dominant model of the ABCB1-C1236T gene polymorphism, but a trend towards response to treatment $(\mathrm{OR} 1.77,95 \% \mathrm{Cl}$ : 1.01-3.1; $p=0.05)[14]$.

Recent studies not included in this meta-analysis have shown conflicting results. One study found an association between TT and CT genotypes and poor response to chemotherapy (OR: 0.35; $95 \mathrm{Cl} \%: 0.13-1.90 ; \mathrm{p}=0.03$ ) [17] in 100 Arabic $\mathrm{BC}$ patients treated with anthracycline-based chemotherapy. Another study performed in 83 Caucasian HER2-positive BC patients treated with chemotherapy plus trastuzumab showed no association, which was likely due to the smaller sample size [16].

\section{$3.3 \quad$ ABCB1-2677 G>T/A}

The ABCB1-G2677T/A gene polymorphism was not associated with response to chemotherapy in 103 Korean MBC patients treated with adjuvant anthracycline plus paclitaxel [18]. This result was confirmed in a another Asian cohort of $153 \mathrm{BC}$ patients treated with neoadjuvant anthracycline-based chemotherapy [13] and in an Indian study of 111 of BC patients treated with neoadjuvant/adjuvant chemotherapy [19].

BC patients (61.5\% HER2-positive) with GG + GT + GA genotypes of the ABCB1G2677T/A gene polymorphism treated with the fluorouracil-doxorubicincyclophosphamide scheme, showed higher resistance to treatment than TT + TA patients. The multivariate analysis showed an OR of $3.19(95 \% \mathrm{Cl}: 0.98-10.39 ; \mathrm{p}=$ 0.053) [20].

The inconsistent conclusions in the association of the ABCB1 C1236T, C3435T and G2677T/A gene polymorphisms and the response to chemotherapy in BC patients led us to conduct a meta-analysis encompassing evidence from all published studies, in order to provide a more precise estimation of the association. 


\section{Material and methods}

\subsection{Study design}

A meta-analysis was carried out.

\subsection{Literature search strategy}

A literature search was carried out using PubMed, Embase, Ovid and Scielo, and included all papers published until December 20th 2016, containing the keywords "ABCB1", "polymorphism", "breast", "cancer" and "response". In order to achieve a comprehensive literature, we also identified additional studies by screening reference lists of key studies or reviews. The literature retrieval was performed in duplication by two independent reviewers (AMP and MCG).

The inclusion criteria used for literature selection were:

1 Original papers.

2 Performed in humans.

3 Studies that explore the association between the three selected SNPS and chemotherapy response.

4 Papers with sufficient data to calculate odds ratio and $95 \%$ confidence interval.

5 Chemotherapy response evaluation by Response Evaluation Criteria In Solid Tumors (RECIST)/ World Health Organisation (WHO) criteria.

6 Papers written in English or Spanish.

The exclusion criteria were:

1 Studies reporting overlapping data.

2 Studies with incomplete data.

3 Studies with duplicated data

\subsection{Data extraction}

Data was carefully extracted from all eligible studies independently by two investigators 
according to the aforementioned inclusion criteria. The following information of the studies were extracted: first author, published year, country, ethnicity, numbers of patients included in the study, genotype frequencies according to chemotherapy response, clinical stage, treatment protocols, genotyping methods and response evaluation criteria. Two reviewers completed the data extraction and reached consensus on all of the extracted data (AMP and MCG). Any discrepancies in the data extraction following this were resolved by a third reviewer (ASP) undertaking data extraction and analysis.

\subsection{Statistical analysis}

The strength of the association between the ABCB1 C3435T, C1236T and G2677T/A gene polymorphisms and the response to $\mathrm{BC}$ treatment therapies was measured with the ORs and their 95\% confidence intervals. First, treatment response was estimated with all the available studies for each polymorphism according to the dominant $(C T+$ TT vs CC), recessive (TT vs $C C+C T$ ) and co-dominant (CT vs $C C$ and TT vs CC) models in the case of the ABCB1 C3435T and C1236T gene polymorphisms. Several models were used for the ABCB1-G2677T/A gene polymorphism (GG + GT + GA vs $T T$ + TA + AA; GG vs GT + GA + TT + TA + AA; GG vs GT + GA; GG vs TT + AA + AT; GT + GA vs TT + AA + AT).

For the meta-analysis, the heterogeneity of the studies was determined using the Cochran $\mathrm{Q}$ chi-square test ( $p<0.05$ was considered as significant heterogeneity), alongside the degree of inconsistency presented as the $\mathrm{I}^{2}$ index where $I^{2}$ of $0-25 \%=$ no heterogeneity; $I^{2}$ of $25-50 \%=$ moderate heterogeneity; $I^{2}$ of $50-75 \%=$ high heterogeneity and $I^{2}$ of $75-100 \%=$ extreme heterogeneity. The combined OR of all studies was calculated using the DerSimonian-Laird random effects model. The effect of the study was considered statistically significant if the confidence interval of the combined OR did not contain 1. The data of each analysis were graphically represented using funnel plots generated by the STATA program (Stata Software 
Package version 10 (StataCorp LP, College Station, Texas, USA)). The bias of publication was analysed by the Begg`s and Egger`s tests.

We analysed the overall effect of all studies for each of the ABCB1 gene polymorphisms, - C3435T, C1236T and G2677T/A, according to ethnicity, tumor type and response criteria. The software used for the meta-analysis was Metadisc [21].

\section{$5 \quad$ RESULTS}

\subsection{Study characteristics}

A total of 44 studies were found with the keywords "ABCB1", "polymorphism", "breast", "cancer", "response".

We excluded 19 studies because they were written in Japanese, they included only pharmacokinetic data or because the analysis was performed in non-BC patients.

Seventeen studies were selected after eliminating all meta-analyses, one article whose drug in study was liposomal doxorubicin, one which considered survival as the dependent variable instead of response, and another which assessed only modifications in the expression of $A B C B 1$. Of these 17, three further articles were discarded. Two had not used the RECIST/WHO criteria as a response measure and the third did not have the response data available for later use. Of the remaining articles, three had been developed by the same research group. The first,(Tulsyan et al. [27]) was excluded because all data had been included in the study by Agarwal et al. [19]. This study [19] was kept for the general analysis as it was the most recently published article and included patients with various types of BC. The third article, by Chaturvedi et al. [14], had also been published by the same research group. This study was used for the subgroup analysis which focused on the type of cancer, as its patients had locally advanced breast cancer (LABC) or metastatic breast cancer (MBC). The information from the final 12 studies included in analysis was extracted according to the gene polymorphism. This resulted in nine articles being included for the ABCB1- 
C3435T gene polymorphism, five for ABCB1-C1236T and three for ABCB1-G2677T/A.

All characteristics for each of the studies are summarised in tables 1 and 2. 
Table 1. Characteristics of the studies included in the meta-analysis.

\begin{tabular}{|c|c|c|c|c|c|c|c|c|c|}
\hline Reference & SNP & Cancer type & $\mathbf{N}$ & Age & $\begin{array}{l}\text { NACT/ } \\
\text { ADJ }\end{array}$ & Scheme & Etnia & $\begin{array}{c}\text { Genotyping } \\
\text { Method }\end{array}$ & $\begin{array}{c}\text { Response } \\
\text { Criteria }\end{array}$ \\
\hline $\begin{array}{c}\text { Kafka et al. } 2003 \\
\text { [22] }\end{array}$ & C3435T & LABC & 68 & $\begin{array}{c}\text { Mean } 53 \\
(27-78)\end{array}$ & NACT & ANTHRACYCLINE-BASED & $\begin{array}{c}\text { GERMAN } \\
\text { (CAUCASIAN) }\end{array}$ & PCR-SEQ & RECIST \\
\hline $\begin{array}{c}\text { Ashariati et al. } 2008 \\
\text { [23] }\end{array}$ & C3435T & LABC & 19 & Median 46.5 & NACT & NA & $\begin{array}{l}\text { INDONESIAN } \\
\text { (ASIAN) }\end{array}$ & PCR-SEQ & RECIST \\
\hline $\begin{array}{c}\text { Chang et al. } 2009 \\
\text { [18] }\end{array}$ & $\begin{array}{c}\text { C3435T } \\
\text { G2677T/A }\end{array}$ & MBC & 103 & Median 49 & ACT & $\begin{array}{c}\text { ANTHRACYCLINE + } \\
\text { PACLITAXEL }\end{array}$ & KOREAN (ASIAN) & PCR-SEQ & RECIST \\
\hline $\begin{array}{c}\text { George et al. } 2009 \\
\text { [24] }\end{array}$ & C3435T & LABC & 76 & Mean 48.7 & NACT & FAC & INDIAN & PCR-RFLP & RECIST \\
\hline $\begin{array}{c}\text { Cizmarikova et al. } \\
\qquad \begin{array}{c}2010 \\
{[25]}\end{array}\end{array}$ & C3435T & LABC & 38 & Mean 55 & NACT & ANTHRACYCLINE-BASED & $\begin{array}{c}\text { SLOVAK } \\
\text { (CAUCASIAN) }\end{array}$ & PCR-RFLP & RECIST \\
\hline $\begin{array}{c}\text { Zhang et al. } 2011 \\
\text { [26] }\end{array}$ & $\begin{array}{l}\text { C3435T } \\
\text { C1236T }\end{array}$ & LABC & 119 & Median 49 & NACT & ANTHRACYCLINE-BASED & CHINESE (ASIAN) & PCR-RFLP & RECIST \\
\hline $\begin{array}{c}\text { Ji et al. } 2012 \\
\text { [13] }\end{array}$ & $\begin{array}{c}\text { C3435T } \\
\text { C1236T } \\
\text { G2677T/A }\end{array}$ & PRIMARY & 153 & Median 48 & NACT & ANTHRACYCLINE-BASED & CHINOS (ASIAN) & PCR-RFLP & WHO \\
\hline Alsaif et al. 2013 & $\mathrm{C} 1236 \mathrm{~T}$ & DE TODOS & 100 & Mean 51.5 & ACT & ANTHRACYCLINE-BASED & ARABIC & TAQMAN & WHO \\
\hline
\end{tabular}




\begin{tabular}{|c|c|c|c|c|c|c|c|c|c|}
\hline [17] & & & & & & & & & \\
\hline $\begin{array}{c}\text { Chaturvedi et al. } 2013 \\
\text { [14] }\end{array}$ & $\begin{array}{l}\text { C3435T } \\
\text { C1236T }\end{array}$ & $\mathrm{LABC}$ y $M B C$ & 100 & NA & $\begin{array}{l}\text { ACT / } \\
\text { NACT }\end{array}$ & FAC/FEC & INDIAN & PCR-RFLP & RECIST \\
\hline $\begin{array}{c}\text { Agarwal et al. } 2015 \\
\text { [19] }\end{array}$ & $\begin{array}{c}\text { C3435T } \\
\text { C1236T } \\
\text { G2677T/A }\end{array}$ & ALL TYPES & 111 & Mean 48.92 & $\begin{array}{l}\text { ACT / } \\
\text { NACT }\end{array}$ & ANTHRACYCLINE-BASED & INDIAN & PCR-RFLP & RECIST \\
\hline $\begin{array}{c}\text { Madrid et al. } 2016 \\
\text { [16] }\end{array}$ & $\begin{array}{l}\text { C3435T } \\
\text { C1236T }\end{array}$ & ALL TYPES & 83 & $\begin{array}{c}\text { Mean } \\
(52 \pm 13)\end{array}$ & ACT/ NACT & ANTHRACYCLINE-BASED & $\begin{array}{c}\text { SPANISH } \\
\text { (CAUCASIAN) }\end{array}$ & TAQMAN & RECIST \\
\hline ACT (Adjuvant C & therapy & $\begin{array}{l}\text { (Breast Cancer } \\
\text { luorouracil-epirut }\end{array}$ & $A B C$ & $\begin{array}{l}\text { ocally Advan } \\
\text { ohosphamide }\end{array}$ & $\begin{array}{l}\text { e Breast Cance } \\
\text {, NA: Not availc }\end{array}$ & $\begin{array}{l}\text { MBC (Metastatic Breast Cance } \\
\text {, NACT (Neoadjuvant Chemot }\end{array}$ & $\begin{array}{l}\text { (Fluorouracil-adri } \\
\text { Seq (Sequencin }\end{array}$ & -cyclophospha & , FEC \\
\hline
\end{tabular}


Table 2. Genotype distribution of the studies included in the meta-analysis.

\begin{tabular}{|c|c|c|c|c|c|c|c|c|c|}
\hline \multirow[t]{2}{*}{ Reference } & \multicolumn{3}{|c|}{$\begin{array}{c}\text { Genotypes } \\
\text { C3435T }\end{array}$} & \multicolumn{3}{|c|}{$\begin{array}{c}\text { Genotypes } \\
\text { C1236T }\end{array}$} & \multicolumn{3}{|c|}{$\begin{array}{l}\text { Genotypes } \\
\text { G2677T/A }\end{array}$} \\
\hline & $\mathrm{CC}$ & CT & TT & $\mathrm{CC}$ & CT & TT & GG & $\begin{array}{c}\text { GT or } \\
\text { GA }\end{array}$ & $\begin{array}{c}\text { TT or AA or } \\
\text { AT }\end{array}$ \\
\hline Kafka et al. 2003 [22] & 14 & 39 & 15 & & & & & & \\
\hline Ashariati et al. 2008 [23] & 0 & 5 & 14 & & & & & & \\
\hline Chang et al. 2009 [18] & 53 & 10 & 40 & & & & 23 & 44 & 36 \\
\hline George et al. 2009 [24] & 8 & 35 & 23 & & & & & & \\
\hline $\begin{array}{l}\text { Cizmarikova et al. } 2010 \\
\text { [25] }\end{array}$ & 5 & 25 & 8 & & & & & & \\
\hline Zhang et al. 2011 [26] & 45 & 53 & 21 & 16 & 64 & 41 & & & \\
\hline Ji et al. 2012 [13] & 34 & 98 & 21 & 19 & 56 & 78 & 26 & 86 & 41 \\
\hline Alsaif et al. 2013 [17] & & & & 73 & 11 & 16 & & & \\
\hline Chaturvedi et al. 2013 [14] & 10 & 49 & 41 & 20 & 44 & 36 & & & \\
\hline Agarwal et al. 2015 [19] & 15 & 50 & 46 & 23 & 48 & 40 & 3 & 54 & 54 \\
\hline Madrid et al. 2016 [16] & 21 & 51 & 11 & 33 & 42 & 8 & & & \\
\hline
\end{tabular}




\subsection{Meta-analysis}

Nine articles were included for the ABCB1-C3435T gene polymorphism (770 patients) to calculate the combined OR (Table 1). There was no association of this polymorphism with the response to chemotherapy in patients with $B C$ in any of the models (dominant, recessive, codominant) (Table 3).

Table 3. Response to chemotherapy depending on different ABCB1-C3435T genetic models and groups of patients (ethnicity/cancer type).

\begin{tabular}{|c|c|c|c|c|c|}
\hline Model & Total or subgroup of patients & $\mathbf{N}$ & OR (95\% Cl) & $\mathrm{I}^{2}(\%)$ & $\mathbf{P}$ \\
\hline \multirow[t]{7}{*}{ Dominant (CT+TT vs CC) } & Global & 8 & $0.888(0.558-1.413)$ & 21.2 & 0.261 \\
\hline & Caucasian & 3 & $1.263(0.193-8.253)$ & 58.4 & 0.090 \\
\hline & Asian & 3 & $0.797(0.497-1.280)$ & 1.7 & 0.362 \\
\hline & Indian & 2 & $1.168(0.334-4.084)$ & 41.2 & 0.192 \\
\hline & All types + primary & 3 & $1.217(0.643-2.302)$ & 6.7 & 0.342 \\
\hline & $\mathrm{LABC}+\mathrm{MBC}$ & 6 & $0.961(0.436-2.119)$ & 46 & 0.099 \\
\hline & RECIST & 7 & $0.807(0.471-1.383)$ & 22.4 & 0.258 \\
\hline \multirow[t]{7}{*}{ Recessive (TT vs CT + CC) } & Global & 8 & $0.993(0.519-1.900)$ & 61.3 & 0.008 \\
\hline & Caucasian & 3 & $0.875(0.316-2.420)$ & 0 & 0.510 \\
\hline & Asian & 3 & $0.965(0.267-3.483)$ & 78.9 & 0.003 \\
\hline & Indian & 2 & $0.948(0.394-2.285)$ & 54.1 & 0.140 \\
\hline & All types + primary & 3 & $2.007(0.695-5.798)$ & 60.7 & 0.078 \\
\hline & $\mathrm{LABC}+\mathrm{MBC}$ & 6 & $0.830(0.455-1.513)$ & 45.1 & 0.091 \\
\hline & RECIST & 8 & $0.812(0.484-1.361)$ & 30.9 & 0,182 \\
\hline \multirow[t]{3}{*}{ CT vs CC } & Global & 8 & $0.834(0.538-1.292)$ & 0 & 0.467 \\
\hline & Caucasian & 3 & $1.077(0.544-2.131)$ & 0 & 0.760 \\
\hline & Asian & 3 & $0.709(0.412-1.220)$ & 75.3 & 0.017 \\
\hline
\end{tabular}




\begin{tabular}{|cccccc|}
\hline Indian & 2 & $1.262(0.468-3.404)$ & 0 & 0.361 \\
All types + primary & 3 & $1.008(0.535-1.898)$ & 0 & 0.466 \\
LABC + MBC & 6 & $1.004(0.426-2.368)$ & 38.8 & 0.147 \\
RECIST & 7 & $0.808(0.467-1.397)$ & 8.4 & 0.364 \\
\hline Global & 8 & $1.146(0.511-2.571)$ & 57 & 0.023 \\
TT vs CC & 3 & $1.244(0.096-16.124)$ & 65 & 0.057 \\
Caucasian & 3 & $1.238(0.366-4.190)$ & 0 & 0.609 \\
Asian & 2 & $1.083(0.215-5.444)$ & 60.3 & 0.113 \\
Indian & 3 & $2.327(0.756-7.161)$ & 41.8 & 0.179 \\
All types + primary & 6 & $0.830(0.455-1.513)$ & 45.1 & 0.091 \\
LABC + MBC & 7 & $0.848(0.415-1.734)$ & 34.0 & 0.168 \\
RECIST & & & \\
\hline N: studies, All types (BC of all stages $)$ &
\end{tabular}

Five studies, with a total of 566 patients were selected for analysis of the ABCB1C1236T gene polymorphism. No association of this polymorphism with the response to chemotherapy was found in patients with BC, in any model (Table 4).

Table 4. Response to chemotherapy depending on different ABCB1-C1236T genetic models and groups of patients (ethnicity/cancer type).

\begin{tabular}{|cccccc|}
\hline Model & $\begin{array}{c}\text { Total or subgroup of } \\
\text { patients }\end{array}$ & $\mathbf{N}$ & OR $(\mathbf{9 5 \%}$ Cl) & $\begin{array}{c}\mathbf{I}^{2} \\
(\%)\end{array}$ & $\mathbf{P}$ \\
\hline Dominant (CT+TT vs CC) & Global & 5 & $1.968(0.609-6.362)$ & 79.9 & 0.001 \\
& Asian & 2 & $0.956(0.453-2.020)$ & 0 & 0.640 \\
& All types & 4 & $\begin{array}{c}2.507(0.596- \\
10.543)\end{array}$ & 82.5 & 0.001 \\
& & & $1.846(0.323-$ & & \\
& LABC + MBC & 2 & $10.545)$ & 76.3 & 0.040 \\
& & & $1.22(0.53-2.82)$ & 39.6 & 0.1912
\end{tabular}




\begin{tabular}{|c|c|c|c|c|c|}
\hline & WHO & 2 & $1.029(0.429-2.469)$ & 0 & 0.5473 \\
\hline \multirow[t]{6}{*}{$\begin{array}{c}\text { Recessive (TT vs CT + } \\
\text { CC) }\end{array}$} & Global & 5 & $1.951(0.690-5.519)$ & 82.2 & 0.000 \\
\hline & Asian & 2 & $1.045(0.390-2.804)$ & 72.5 & 0.057 \\
\hline & All types & 4 & $2.753(0.814-9.307)$ & 80.7 & 0.001 \\
\hline & $L A B C+M B C$ & 2 & $0.845(0.446-1.601)$ & 20.3 & 0.263 \\
\hline & RECIST & 3 & $0.909(0.531-1.556)$ & 0 & 0,399 \\
\hline & WHO & 2 & $1.376(0.814-2.325)$ & 0 & 0,480 \\
\hline \multirow[t]{6}{*}{ CT vs CC } & Global & 5 & $1.384(0.576-3.323)$ & 55.4 & 0.062 \\
\hline & Asian & 2 & $0.867(0.390-1.928)$ & 0 & 0.827 \\
\hline & All types & 4 & $1.578(0.498-5.001)$ & 64.9 & 0.036 \\
\hline & $L A B C+M B C$ & 2 & $\begin{array}{c}2.117(0.399- \\
11.233)\end{array}$ & 72 & 0.059 \\
\hline & RECIST & 3 & $1.275(0.362-4.487)$ & 68.1 & 0.044 \\
\hline & WHO & 2 & $1.720(0.278-10.632)$ & 63.7 & 0,097 \\
\hline \multirow[t]{6}{*}{ TT vs CC } & Global & 5 & $2.472(0.610-10.019)$ & 80.5 & 0.000 \\
\hline & Asian & 2 & $0.963(0.408-2.271)$ & 13.1 & 0.283 \\
\hline & All types & 4 & $\begin{array}{c}3.660(0.754- \\
17.757)\end{array}$ & 79.1 & 0.002 \\
\hline & $\mathrm{LABC}+\mathrm{MBC}$ & 2 & $1.498(0.227-9.897)$ & 76.3 & 0.040 \\
\hline & RECIST & 3 & $1.246(0.320-4.861)$ & 60 & 0.082 \\
\hline & WHO & 2 & $\begin{array}{c}7.106(0.278- \\
181.59)\end{array}$ & 91.7 & 0.001 \\
\hline \multicolumn{6}{|c|}{$\mathrm{N}$ : studies, All types (BC of all stages) } \\
\hline
\end{tabular}

After the stratification by ethnicity, type of cancer and the criteria to measure the response according to the dominant, recessive or codominant models, no influence of these factors was found to be associated with the response to chemotherapy in BC 
patients for either the ABCB1 C3435T (Table 3, Figures 1 and 2) or C1236T (Table 4, Figure 3) gene polymorphisms.

Figure 1. Forest plot of the dominant model of ABCB1-C3435T gene polymorphism by ethnicity.

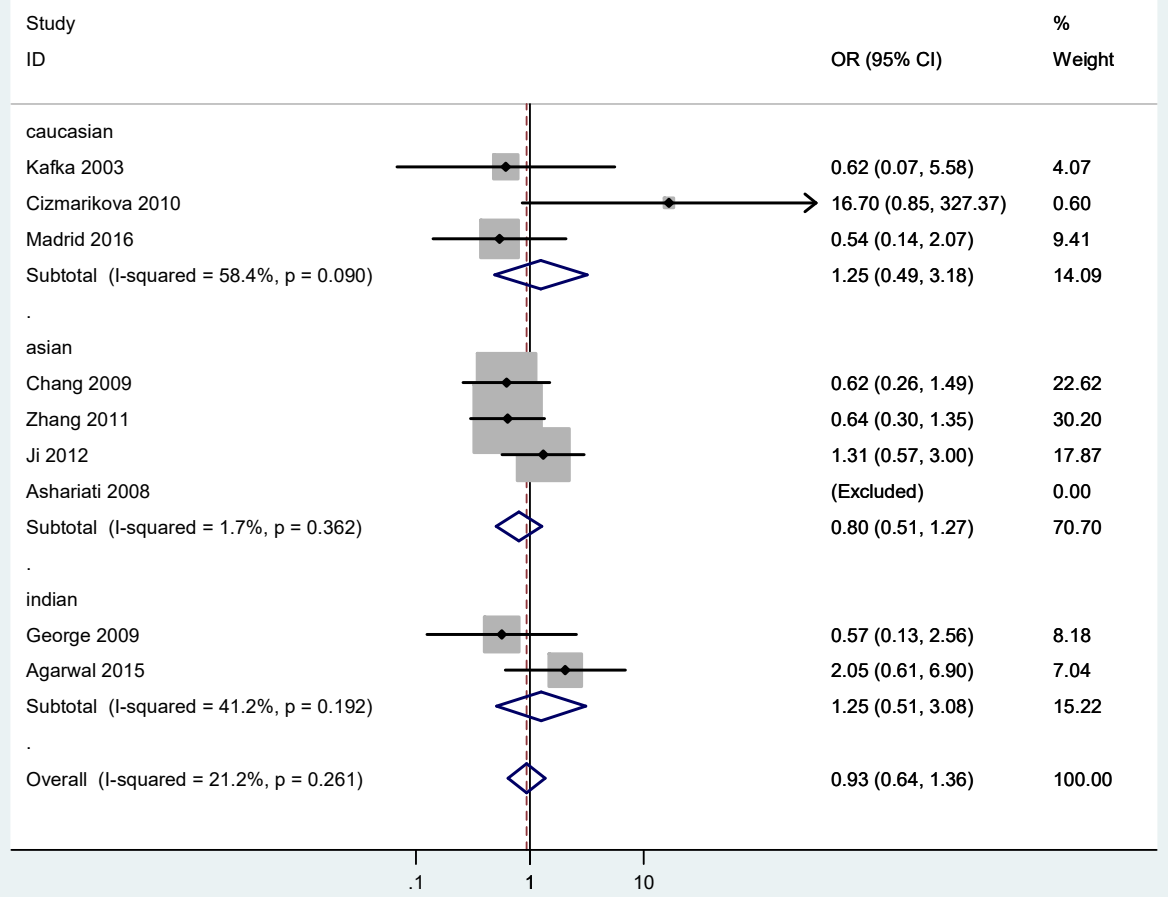


Figure 2. Forest plot of the dominant model of ABCB1-C3435T gene polymorphism by cancer type.

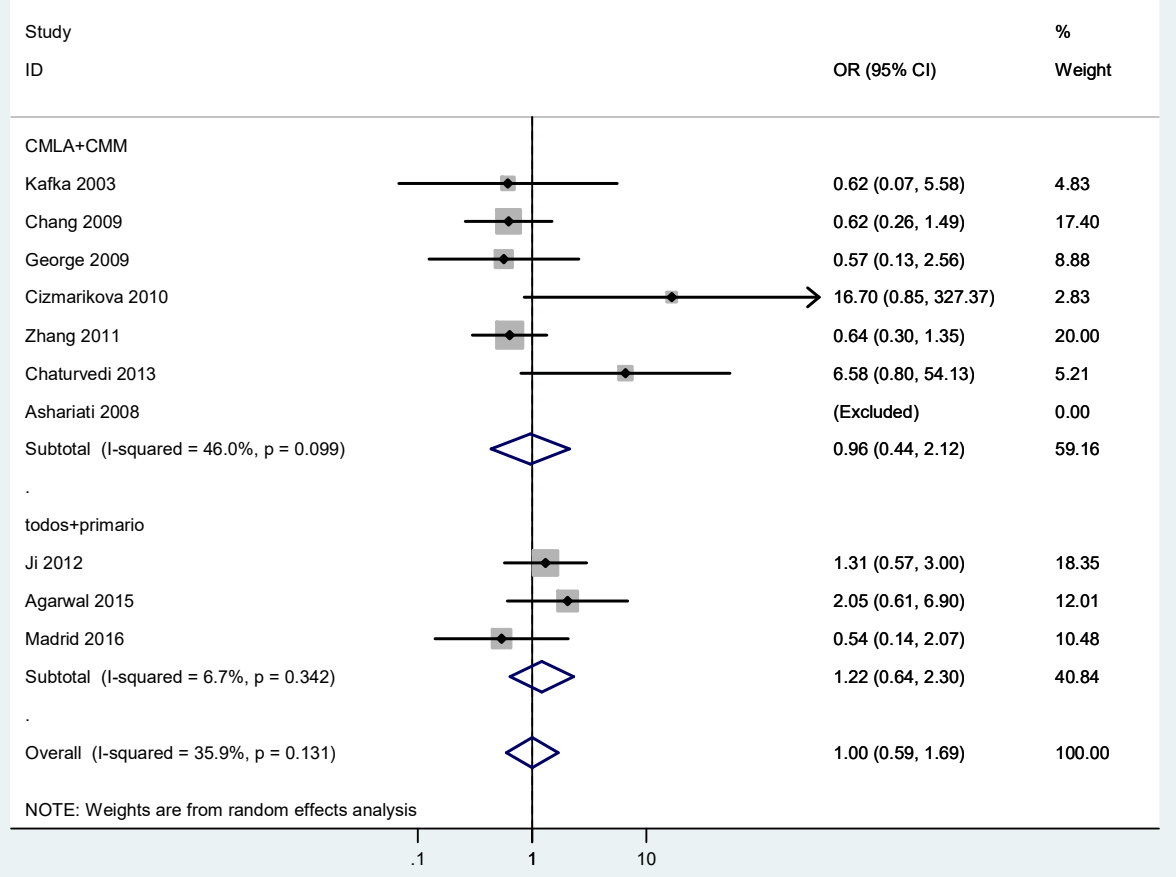


Figure 3. Forest plot of the dominant model of ABCB1-C1236T gene polymorphism by the criteria measurement of the response.

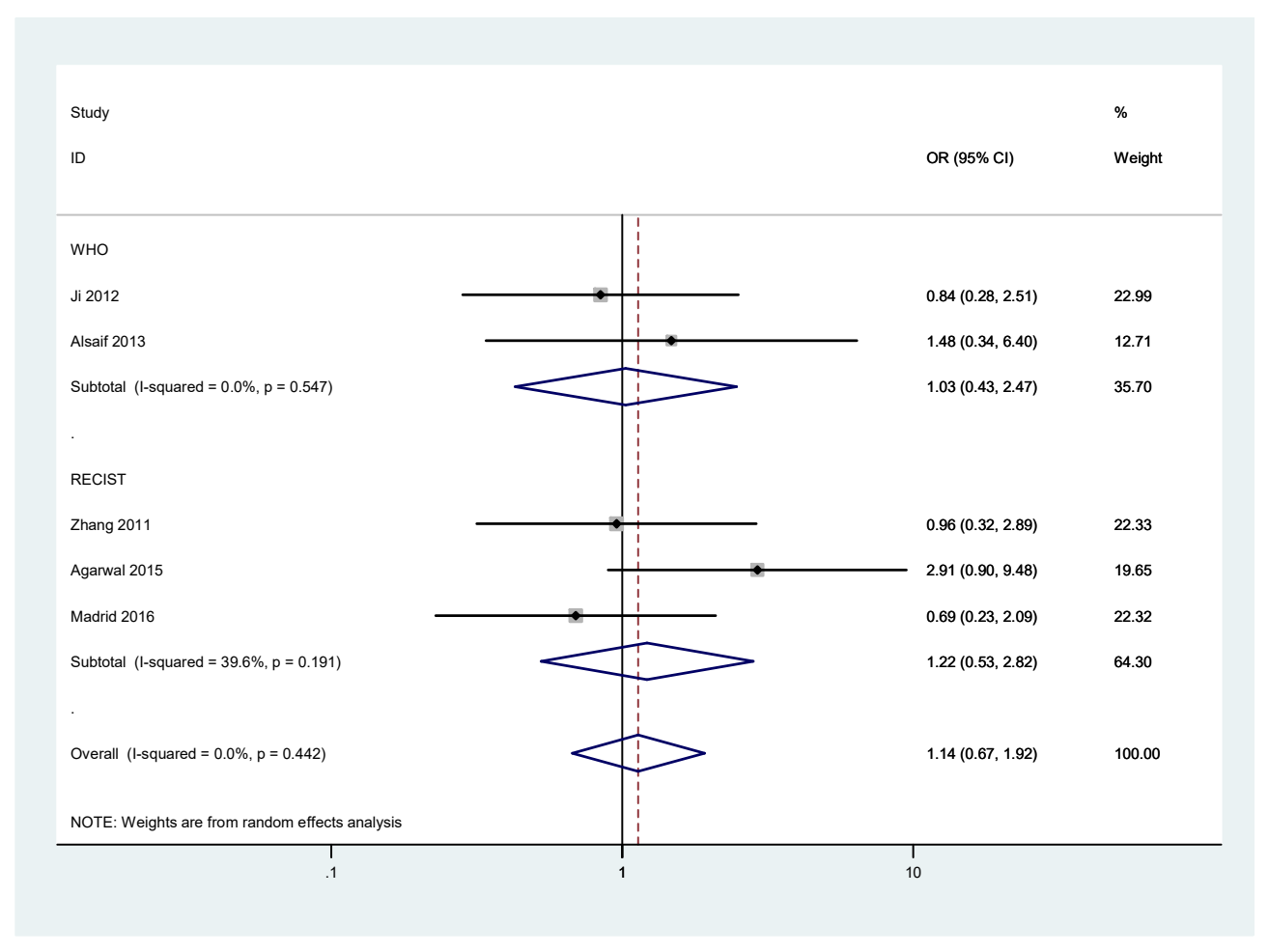

The meta-analysis for ABCB1-G2677T/A which included three studies and 367 patients, did not reveal an association between the polymorphism and the response to chemotherapy (table 4). No association between the ABCB1-G2677T/A gene polymorphism and response to chemotherapy was found after stratification by ethnicity (two studies in Asian population) or cancer type (two studies of all types of cancer) in any model (table 5).

Table 5. Response to chemotherapy depending on different ABCB1-G2677T/A genetic models and groups of patients (ethnicity/cancer type).

\begin{tabular}{|c|c|c|c|c|c|}
\hline Model & $\begin{array}{c}\text { Total or subgroup of } \\
\text { patients }\end{array}$ & $\mathbf{N}$ & OR $(95 \% \mathrm{Cl})$ & $\begin{array}{c}1^{2} \\
(\%)\end{array}$ & $\mathbf{P}$ \\
\hline \multirow[t]{2}{*}{$\begin{array}{c}G G+G T+G A \text { vs } T T+T A+ \\
A A\end{array}$} & Global & 3 & $0.804(0.506-1.278)$ & 0 & 0.912 \\
\hline & Asian & 2 & $\begin{array}{c}0.779(0.434- \\
1.400)\end{array}$ & 0 & 0.694 \\
\hline
\end{tabular}




\begin{tabular}{|c|c|c|c|c|c|}
\hline & All types & 2 & $\begin{array}{c}0.851(0.500- \\
1.450)\end{array}$ & 0 & 0.986 \\
\hline \multirow[t]{3}{*}{$\begin{array}{c}\mathrm{GG} \text { vs } \mathrm{GT}+\mathrm{GA}+\mathrm{TT}+\mathrm{TA}+ \\
\mathrm{AA}\end{array}$} & Global & 3 & $0.854(0.418-1.744)$ & 3.1 & 0.356 \\
\hline & Asian & 2 & $\begin{array}{c}0.934(0.442- \\
1.973)\end{array}$ & 8.3 & 0.296 \\
\hline & All types & 2 & $\begin{array}{c}0.602(0.246- \\
1.475)\end{array}$ & 0 & 0.444 \\
\hline \multirow[t]{3}{*}{ GG vs $G T+G A$} & Global & 3 & $0.929(0.374-2.308)$ & 25.6 & 0.261 \\
\hline & Asian & 2 & $\begin{array}{c}1.071(0.406- \\
2.825)\end{array}$ & 39.2 & 0.200 \\
\hline & All types & 2 & $\begin{array}{c}0.614(0.243- \\
1.550)\end{array}$ & 0 & 0.453 \\
\hline \multirow[t]{3}{*}{$G G$ vs $T T+A A+A T$} & Global & 3 & $0.708(0.321-1.560)$ & 0 & 0.575 \\
\hline & Asian & 2 & $\begin{array}{c}0.780(0.344- \\
1.769)\end{array}$ & 0 & 0.573 \\
\hline & All types & 2 & $\begin{array}{c}0.557(0.203- \\
1.533)\end{array}$ & 0 & 0.456 \\
\hline \multirow[t]{3}{*}{$\mathrm{GT}+\mathrm{GA}$ vs TT + AA + AT } & Global & 3 & $\begin{array}{c}0.824(0.511- \\
1.330)\end{array}$ & 0 & 0.673 \\
\hline & Asian & 2 & $\begin{array}{c}0.765(0.414- \\
1.412)\end{array}$ & 0 & 0.422 \\
\hline & All types & 2 & $\begin{array}{c}0.928(0.538- \\
1.599)\end{array}$ & 0 & 0.997 \\
\hline \multicolumn{6}{|c|}{$\mathrm{N}$ : studies, All types (BC of all stages) } \\
\hline
\end{tabular}

\subsection{Test for heterogeneity}

The heterogeneity of the studies used in each comparison of the ABCB1 C3435T and C1236T gene polymorphisms and response to chemotherapy, were diverse. These are detailed in Tables 3, 4 and 5 and include the degree of inconsistent data ( $I^{2}$ index) and the Cochran $Q$ chi-square test (heterogeneity: $p<0.05$ ). Heterogeneity was higher for the ABCB1-C1236T polymorphism models. 


\subsection{Publication bias}

The dominant model of ABCB1-C3435T did not present publication bias, calculated by the Begg test $(p=0.293 ; p$ continuity corrected $=0.368)$ and the Egger test results $(p=$ $0.891)$.

Similarly, there was no publication bias in the dominant model of ABCB1-C1236T, according to the Begg $(p=0.73 ; p$ continuity corrected $=0.462)$ and the Egger test $(p=$ 0.470). The graphical representations of these tests are shown below (Figures 4 and $5)$.

Figure 4. Begg's funnel plot for publication bias test (ABCB1-C3435T dominant model).

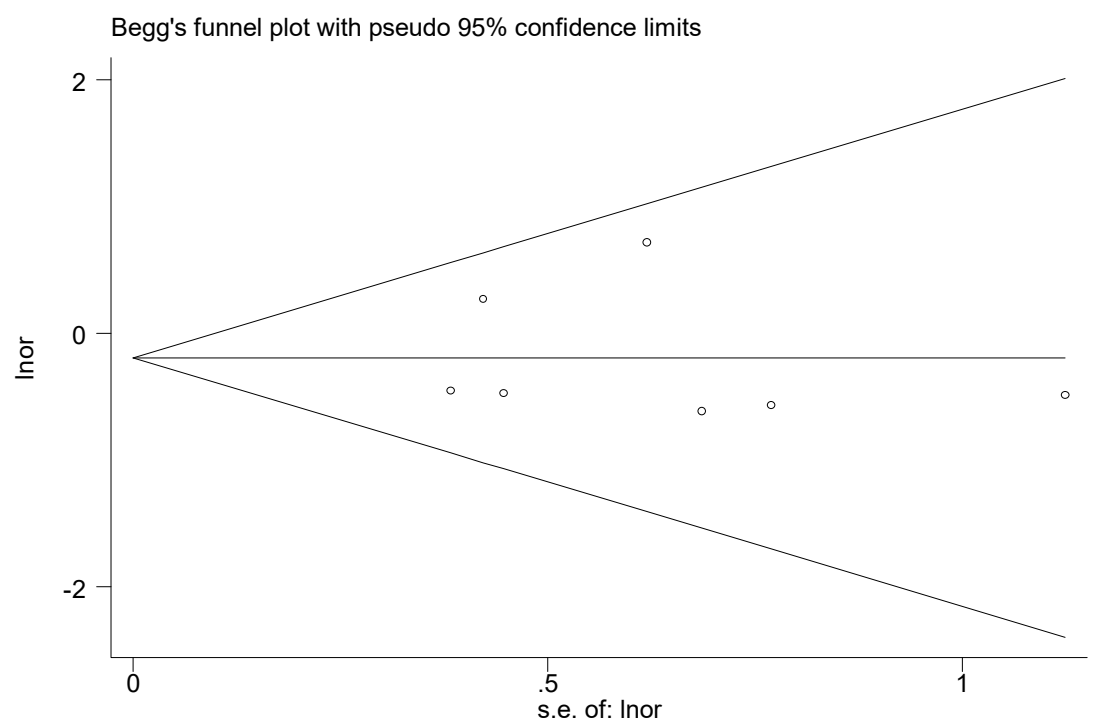


Figure 5. Begg's funnel plot for publication bias test (ABCB1-C1236T dominant model).

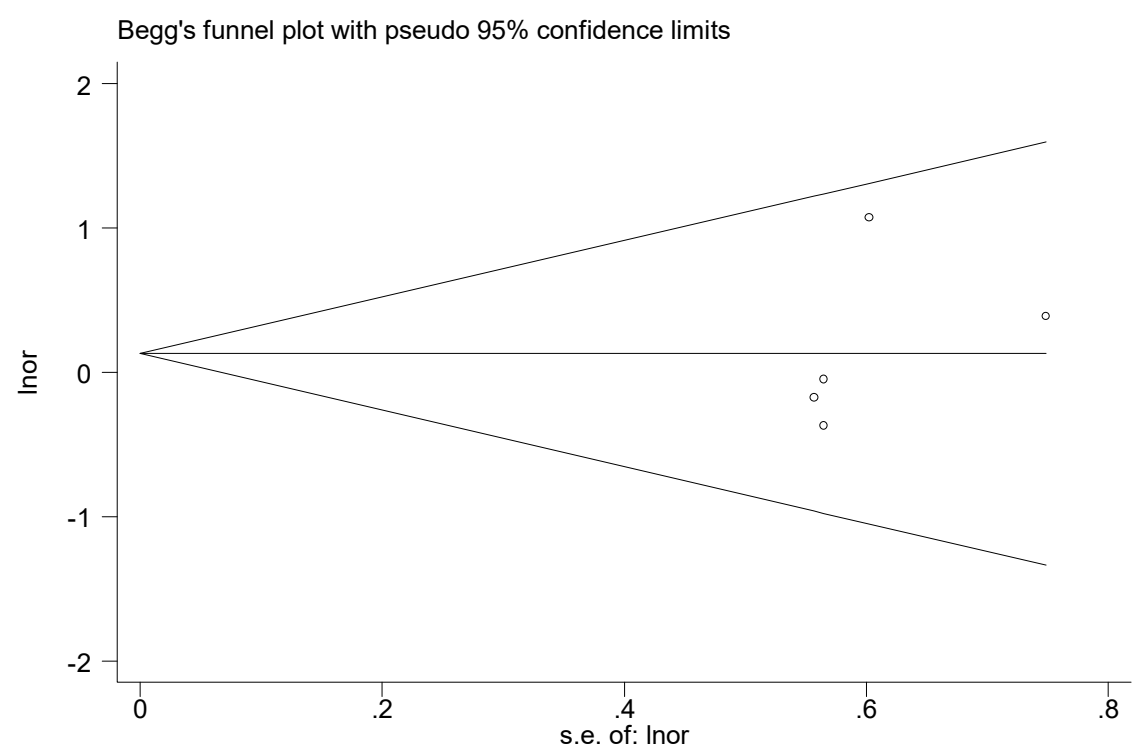

The model (GG vs GT + GA + TT + TA + AA) of ABCB1-G2677T/A did not present publication bias as showed by the Begg test $(p=0.317 ; p$ continuity corrected $=1.0)$ (Figure 6).

Figure 6. Begg's funnel plot for publication bias test (ABCB1-G2677T/A GG vs GT + $\mathrm{GA}+\mathrm{TT}+\mathrm{TA}+\mathrm{AA}$ model)

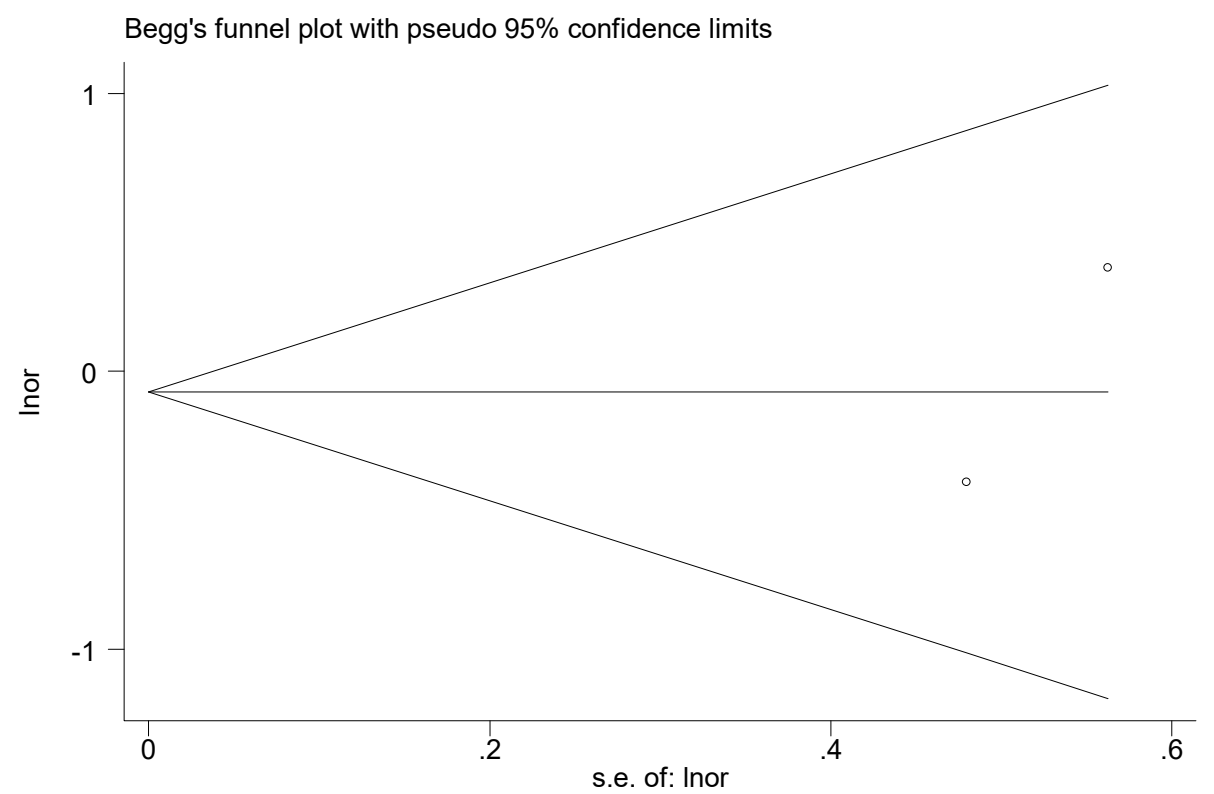




\section{DISCUSSION}

Current therapeutic management of patients with HER2 positive BC, including various combinations of chemotherapeutic agents, HER2 targeting drugs and hormone therapy, has greatly improved the outcomes in these patients. Although these schemes often achieve favorable results, response to treatments remains a challenge for clinicians. ABCB1 gene polymorphisms have been proposed as potential predictors of response to chemotherapy. In the present study, we performed a meta-analysis to evaluate the association between the $A B C B 1$ gene polymorphism and response to chemotherapy.

The association of the $A B C B 1-C 3435 T$ polymorphism and response in $B C$ patients treated with neoadjuvant chemotherapy was initially suggested in a study of 68 patients with locally advanced BC who showed better clinical response in patients carrying the TT genotype of ABCB1-C3435T (OR: 4.38, 95\% Cl: 1.2-16.1, p = 0.029) [22]. In two meta-analyses, one published in 2012 which included 464 patients [11] and the second published in 2013 which included 608 individuals \{Chaturvedi: 2013ch\}, the ABCB1C3435T gene did not influence the response to treatment. Other studies have attempted to refute this lack of association with response to treatment, but have failed to find consistency in the effect of the $T$ allele on clinical outcome. In a study of Chinese BC patients, those with the ABCB1-C3435T $\mathrm{T}$ allele showed an improved response to neoadjuvant chemotherapy $(43.4 \%$ vs $23.8 \%$, OR: $2.695, p=0.02)$ [12]. Conversely, patients with TT genotype of ABCB1-C3435T showed a poorer response to neoadjuvant chemotherapy (33.3 vs. $71.2 \%, p=0.001)$ [13].

Our meta-analysis included 770 patients from nine studies confirmed the absence of the association between the response to chemotherapy and ABCB1-C3435T. These results are in agreement with the meta-analysis by Chen et al. [11] and Chaturvedi et al. [14]. The meta-analysis by Chen et al. included seven studies (464 patients), three of which included Caucasian populations, three which included Asian populations and 
one included a mixed ethnic group (Brazilians). All patients had BC in advanced stages (6 LABC and $1 \mathrm{MBC}$ ), and the sample size of the studies varied between 19-119 cases. The meta-analysis published by Chaturvedi et al. encompassed 608 patients from 8 studies. Each of the included studies, were also assessed in the meta-analysis by Chen et al., with the exception of the study by Ji et al. [13], which was conducted in an Asian population, and data from their own study, focused on an Indian population [14].

In our meta-analysis, the stratified analysis by types of cancer (primary + all types vs $\mathrm{LABC}+\mathrm{MBC}$ ), also showed no association with the response to chemotherapy in any genetic model of the ABCB1-C3435T polymorphism, with a high heterogeneity, especially in the subgroup of patients with $L A B C+M B C\left(I^{2}=46.0 \% ; p=0.099\right)$.

Other polymorphisms in $\mathrm{ABCB} 1$ have been explored as biomarkers of response. The T-allele of the ABCB1-C1236T gene polymorphism was associated with a poorer response $(58.3 \%$ vs $85 \%$, OR non-responders/responders: $4.63 ; p=0.021)$ in 100 Indian $B C$ patients treated with neoadjuvant chemotherapy, cyclophosphamide plus epirubicin or doxorubicin) $[15,19]$. A similar trend was demonstrated by carriers of the $T$ allele in a small cohort of 58 patients treated with neoadjuvant chemotherapy $(57.4 \%$ vs. $81.8 \%$, OR non-responders/responders: $3.33 ; p=0.150$ ), but without a statistically significant association, which is most likely due to the small sample size [27]. In our metaanalysis, the ABCB1-C1236T genetic polymorphism did not influence the response. The different genetic models (dominant, recessive and co-dominant) of ABCB1C1236T were not associated with the response to chemotherapy in the global metaanalysis. Stratification by ethnicity, cancer type and response measurement criteria did not provide information about the possible influence of these variables on the response to chemotherapy in BC patients. This data is in line with the meta-analysis including 373 patients, conducted by an Indian research group, comprising three studies, two in Asian population, and their results in Indian population. They did not find an 
association between the $\mathrm{ABCB} 1-\mathrm{C} 1236 \mathrm{~T}$ gene polymorphism and response to chemotherapy in patients with $\mathrm{BC}$, although a trend was shown $(\mathrm{OR}: 1.77 ; 95 \% \mathrm{Cl}$ : 1.01-3.10; $p=0.05$ ) [14]. Our meta-analysis included all studies to date with a total of five (566 patients), increasing the accuracy of the study, and thus confirming the nonassociation of this polymorphism with the response to chemotherapy in $\mathrm{BC}$ patients.

The ABCB1-G2677T/A gene polymorphism was not associated with response to chemotherapy in 103 Korean MBC patients treated with adjuvant anthracycline plus paclitaxel [18]. This result was confirmed in a another Asian cohort of $153 \mathrm{BC}$ patients treated with neoadjuvant anthracycline-based chemotherapy [13] and in an Indian study of 111 of BC patients treated with neoadjuvant/adjuvant chemotherapy [19]. Our meta-analysis included three studies (two in Asian population and one in an Indian population), and did not find an association between the ABCB1-G2677T/A, different genetic models and the response to chemotherapy.

These meta-analyses showed no association between ABCB1 polymorphisms and response to chemotherapy, despite some studies having shown contradictory results. Possible causes of these differences may be the complexity of the phenomenon and gene-gene interactions [28]. Some intracellular alterations, as other unknown ABCB1 polymorphisms and errors in the posttranslational modification in the protein structure of P-glicoprotein, might balance the effect of these polymorphisms.

In our meta-analysis, one limitation is the high heterogeneity that has been found in the different comparisons, especially in relation to the ABCB1-C1236T gene polymorphism. This heterogeneity could be due to the fact that the analysis encompasses few studies, five in the global analysis, and fewer in the subgroup analyses.

The evidence provided by this work indicates that the ABCB1 C3435T, C1236T and G2677T/A gene polymorphisms are not associated with the response to chemotherapy in BC patients. No influence of ethnicity, cancer type and response criteria has been 
found. Subsequent studies focused on other polymorphisms could clarify the importance of this gene in the response to chemotherapy.

\section{ACKNOWLEDGMENTS}

The results of this investigation are part of the doctoral thesis presented by Adela Madrid-Paredes at the University of Granada.

\section{REFERENCES}

[1] WHO, OMS | Cáncer de mama: prevención y control, Who. (n.d.).

[2] NCCN. Clinical Practice Guidelines in Oncology. NCCN Guidelines. Breast Cancer. Version 2.2015, (2001) 1-166.

[3] Polychemotherapy for early breast cancer: an overview of the randomised trials. Early Breast Cancer Trialists' Collaborative Group, Lancet. 352 (1998) 930-942.

[4] P.P. Gor, H.I. Su, R.J. Gray, P.A. Gimotty, M. Horn, R. Aplenc, et al., Cyclophosphamide-metabolizing enzyme polymorphisms and survival outcomes after adjuvant chemotherapy for node-positive breast cancer: a retrospective cohort study, Breast Cancer Res. 12 (2010) R26. doi:10.1186/bcr2570.

[5] M. Clarke, A.S. Coates, S.C. Darby, C. Davies, R.D. Gelber, J. Godwin, et al., Adjuvant chemotherapy in oestrogen-receptor-poor breast cancer: patient-level meta-analysis of randomised trials, Lancet. $371 \quad$ (2008) 29-40. doi:10.1016/S0140-6736(08)60069-0.

[6] M.F. Fromm, The influence of MDR1 polymorphisms on P-glycoprotein expression and function in humans, Adv. Drug Deliv. Rev. 54 (2002) 12951310.

[7] S.-F. Zhou, Structure, function and regulation of P-glycoprotein and its clinical relevance in drug disposition, Xenobiotica. 38 (2008) 802-832. doi:10.1080/00498250701867889. 
[8] F. Leonessa, R. Clarke, ATP binding cassette transporters and drug resistance in breast cancer, Endocr. Relat. Cancer. 10 (2003) 43-73.

[9] A.J.-L. Brambila-Tapia, MDR1 (ABCB1) polymorphisms: functional effects and clinical implications, Rev. Invest. Clin. 65 (2013) 445-454.

[10] R.B. Kim, B.F. Leake, E.F. Choo, G.K. Dresser, S.V. Kubba, U.I. Schwarz, et al., Identification of functionally variant MDR1 alleles among European Americans and African Americans, Clin. Pharmacol. Ther. 70 (2001) 189-199. doi:10.1067/mcp.2001.117412.

[11] G. Chen, S. Quan, Q. Hu, L. Wang, X. Xia, J. Wu, Lack of association between MDR1 C3435T polymorphism and chemotherapy response in advanced breast cancer patients: evidence from current studies, Mol. Biol. Rep. 39 (2012) 5161-5168. doi:10.1007/s11033-011-1312-2.

[12] H. Wu, H. Kang, Y. Liu, W. Tong, D. Liu, X. Yang, et al., Roles of ABCB1 gene polymorphisms and haplotype in susceptibility to breast carcinoma risk and clinical outcomes, J. Cancer Res. Clin. Oncol. 138 (2012) 1449-1462. doi:10.1007/s00432-012-1209-z.

[13] M. Ji, J. Tang, J. Zhao, B. Xu, J. Qin, J. Lu, Polymorphisms in genes involved in drug detoxification and clinical outcomes of anthracycline-based neoadjuvant chemotherapy in Chinese Han breast cancer patients, Cancer Biol. Ther. 13 (2012) 264-271. doi:10.4161/cbt.18920.

[14] P. Chaturvedi, S. Tulsyan, G. Agarwal, P. Lal, S. Agarwal, R.D. Mittal, et al., Influence of $\mathrm{ABCB} 1$ genetic variants in breast cancer treatment outcomes, Cancer Epidemiol. 37 (2013) 754-761. doi:10.1016/j.canep.2013.04.012.

[15] H. Ghafouri, B. Ghaderi, S. Amini, B. Nikkhoo, M. Abdi, A. Hoseini, Association of $A B C B 1$ and $A B C G 2$ single nucleotide polymorphisms with clinical findings and response to chemotherapy treatments in Kurdish patients with breast cancer, Tumour Biol. 37 (2016) 7901-7906. doi:10.1007/s13277-015-4679-1.

[16] A. Madrid Paredes, M. Cañadas-Garre, A. Sánchez-Pozo, A.M. Segura-Pérez, 
C. Chamorro-Santos, E. Vergara-Alcaide, et al., ABCB1 C3435T gene polymorphism as a potential biomarker of clinical outcomes in HER2-positive breast cancer patients, Pharmacol. Res. 108 (2016) 111-118. doi:10.1016/j.phrs.2016.04.016.

[17] A.A. Alsaif, T.N. Hasan, G. Shafi, N.A. Syed, M.A. Alsaif, A.H. Al-Assaf, et al., Cancer Epidemiology, Cancer Epidemiol. $37 \quad$ (2013) 762-766. doi:10.1016/j.canep.2013.04.011.

[18] H. Chang, S.Y. Rha, H.-C. Jeung, C.-K. Im, J.B. Ahn, W.S. Kwon, et al., Association of the ABCB1 gene polymorphisms $2677 \mathrm{G}>\mathrm{T} / \mathrm{A}$ and $3435 \mathrm{C}>\mathrm{T}$ with clinical outcomes of paclitaxel monotherapy in metastatic breast cancer patients, Annals of Oncology. $20 \quad$ (2009) 272-277. doi:10.1093/annonc/mdn624.

[19] G. Agarwal, S. Tulsyan, P. Lal, B. Mittal, Generalized Multifactor Dimensionality Reduction (GMDR) Analysis of Drug-Metabolizing EnzymeEncoding Gene Polymorphisms may Predict Treatment Outcomes in Indian Breast Cancer Patients, World Journal of Surgery. (2015) 1-11. doi:10.1007/s00268-015-3263-6.

[20] K. Tecza, J. Pamula-Pilat, J. Lanuszewska, E. Grzybowska, Genetic polymorphisms and response to 5-fluorouracil, doxorubicin and cyclophosphamide chemotherapy in breast cancer patients, Oncotarget. (2016). doi:10.18632/oncotarget.11053.

[21] J. Zamora, V. Abraira, A. Muriel, K. Khan, A. Coomarasamy, Meta-DiSc: a software for meta-analysis of test accuracy data, BMC Med Res Methodol. 6 (2006) 31. doi:10.1186/1471-2288-6-31.

[22] A. Kafka, G. Sauer, C. Jaeger, R. Grundmann, R. Kreienberg, R. Zeillinger, et al., Polymorphism C3435T of the MDR-1 gene predicts response to preoperative chemotherapy in locally advanced breast cancer, Int J Oncol. 22 (2003) 1117-1121. 
[23] A. Ashariati, Polymorphism C3435T of the MDR-1 gene predict response to preoperative chemotherapy in locally advanced breast cancer with Her2/neu expression, Acta Med Indones. 40 (2008) 187-191.

[24] J. George, K. Dharanipragada, S. Krishnamachari, A. Chandrasekaran, S.S. Sam, E. Sunder, A Single-Nucleotide Polymorphism in the MDR1 Gene as a Predictor of Response to Neoadjuvant Chemotherapy in Breast Cancer, Clinical Breast Cancer. 9 (2009) 161-165. doi:10.3816/CBC.2009.n.026.

[25] M. Cizmarikova, M. Wagnerova, L. Schonova, V. Habalova, A. Kohut, A. Linkova, et al., MDR1 (C3435T) polymorphism: relation to the risk of breast cancer and therapeutic outcome, Pharmacogenomics J. 10 (2010) 62-69. doi:10.1038/tpj.2009.41.

[26] B.-L. Zhang, T. Sun, B.-N. Zhang, S. Zheng, N. Lü, B.-H. Xu, et al., Polymorphisms of GSTP1 is associated with differences of chemotherapy response and toxicity in breast cancer, Chin. Med. J. 124 (2011) 199-204.

[27] S. Tulsyan, P. Chaturvedi, A.K. Singh, G. Agarwal, P. Lal, S. Agrawal, et al., Assessment of clinical outcomes in breast cancer patients treated with taxanes: multi-analytical approach, Gene. $543 \quad(2014) \quad 69-75$. doi:10.1016/j.gene.2014.04.004.

[28] A. Ashworth, C.J. Lord, J.S. Reis-Filho, Genetic interactions in cancer progression and treatment, Cell. $145 \quad$ (2011) 30-38. doi:10.1016/j.cell.2011.03.020. 